\title{
CONIDIAL DISCHARGE OF AN ENTOMOPATHOGENIC FUNGUS INFECTING THE COTTON LEAFHOPPER $\underline{1}$
}

\author{
Cristita Verna Q. Subere \\ Dole Philippines, Inc. \\ Polomolok, South Cotabato
}

ABSTRACT

A laboratory experiment was conducted to determine the conidial discharge of Batkoa amrascae Keller \& Villacarlos, an entomopathogenic fungus found infecting the cotton leafhopper on okra. Field and laboratory-infected leafhopper cadavers were tested for the effect of light. The fungus from field-infected cadavers kept in the dark during sporulation produced an average of 26,372 conidia ( $29 \mathrm{hr}$. mean time conidial production), whereas those exposed to light had 5,290 conidia ( $33 \mathrm{hr}$. mean time conidial production). On the other hand, laboratory-infected cadavers exposed to light attained an average of 4,447 conidia while that of cadavers kept in the dark had 3,373 conidia, both had $28 \mathrm{hr}$ mean time conidial production.

KEY WORDS: Conidial discharge.Entomopathogenic fungi. Batkoa amrascae. Biological control. Cotton leafhopper. Amrasca biguttula.

11 Part of M.S. thesis of the author. 


\section{INTRODUCTION}

Several pests have been reported to attack okra (Ahelmoschus esculentus L. Moench) among which the cotton leafhopper, Amrasca biguttula Ishida, is the most important (Peter and David, 1988). The cotton leafhopper usually inhabits the nether surface of the leaves, hence it is difficult to control heavy infestations even with weekly or twice-weekly application of insecticides. The quick growth and frequent harvest of fruits also preclude the possibility of using insecticides for control due to residue problems (Uthamasamy, "1986). "Hence, the possible use of other control alternatives is imperative.

An entomopathogenic fungus, Batkoa amrascae Keller and Villacarlos, has been identified as a potential biological control agent of cotton leafhopper attacking okra. In only a few days, B. amrascae is observed to destroy the okra leafhopper population in the field.

No research has been conducted in the Philippines on the pathological, biological and ecological characteristics of this entomopathogenic fungus. Considering its potential as a biological control agent, this study was conducted to gather information on conidial discharge and sporulation from individual okra lèafhopper cadavers and determine the effect of light exposure on conidial production. 


\section{METHODOLOGY}

\section{Mass Rearing of Cotton Leafhoppers}

Healthy adult leafhoppers collected from the field were placed inside a $61 \times 122 \times 56 \mathrm{~cm}$ screen cage and were provided with 1month old potted okra plants. Adults were allowed to mate until enough insects of known age were available.

\section{Source of Infected Insects}

\section{Field-infected leafhopper cadavers}

Field-infected adult leafhoppers that had not yet sporulated were carefully removed from the okra leaf substrate where they get attached by the fungal rhizoid. The cadavers were placed in a sterile petri plate, air-dried for 2-3 days and kept dry inside the refrigerator prior to their use in the experiment.

\section{Laboratory-infected leafhopper cadavers}

Several field-infected leafhopper cadavers were used to infect healthy leafhoppers under laboratory condition. Okra leaf discs $(4.3$ $\mathrm{mm}$ in diameter) were placed individually in screw cap vials $(11.3 \mathrm{~mm}$ in length, $4.5 \mathrm{~mm}$ in diameter) bottom-lined with moist filter paper prior to introduction of healthy leafhoppers. Ten (10) healthy adult leathoppers were removed from the rearing cage using a Macaulay battery-operated respirator and transferred into screw cap vials. For each vial, five (5) leafhoppers were placed inside together with one field-infected cadaver. The cadaver was attached to the center of a clean glass slide using a small portion of water agar. The slide was placed upside down on top of the mouth of the vial containing the insects. Sporulating 18 
cadavers were allowed to shower conidia on the healthy leafhopper adults for 15 hours. Dead leafhopper adults were then collected and air-dried.

\section{Laboratory Set-up on Conidial Discharge}

Ten (10) newly field-infected leafhopper adults and another batch of 10 laboratory infected insects that had not yet sporulated were used in the study. The cadavers were placed singly in the middle of the petri plate lined with moistened filter paper. A glass slide supported with a rubber band (about $2 \mathrm{~mm}$ thickness) was placed on top of the cadaver to catch the forcibly discharged conidia. Every 30 minutes, the exposed glass slide was replaced with a clean one until all the conidia were properly labelled based on the time it was removed above the sporulating cadaver. Each slide was flooded with lactophenol cotton blue, covered with a cover slip and examined under the microscope. The number of conidia collected on the slides was counted using a compound microscope. To determine if there was any effect of light on conidiation, the first batch of 5 cadavers (either field of laboratory infected) were exposed to continuous light using two 40watts fluorescent bulb while the remaining 5 were kept in the dark. The release of conidia was monitored every $30 \mathrm{~min}$. Light intensity during conduct of the study was determined using a light meter.

\section{RESULTS AND DISCUSSION}

\section{Conidial Production of Field-Infected Leafhopper Cadavers}

The number of discharged conidia from cadavers exposed to light and those produced in the dark varied greatly depending on the individuals (Fig. 1). Cadavers from both set-up started initial conidiation 


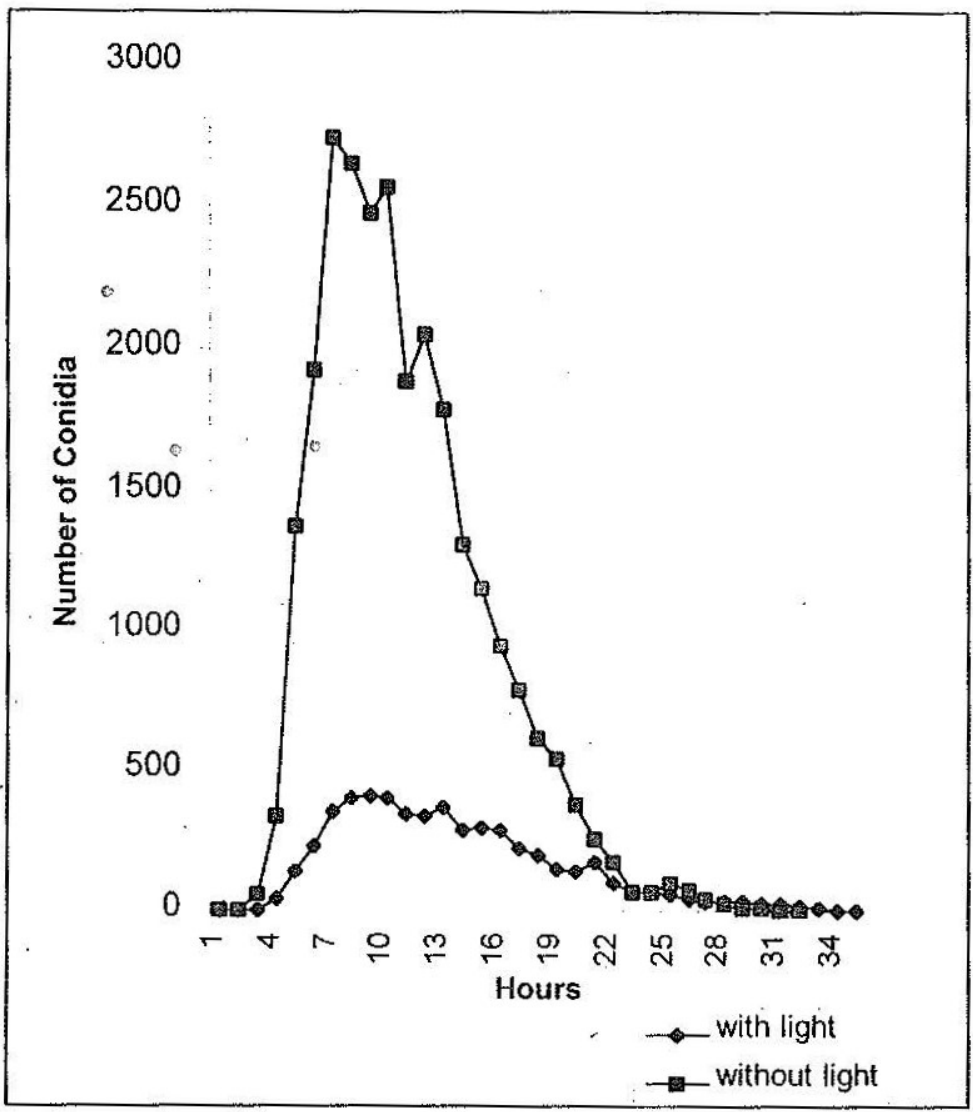

Figure 1. Average number of Batkoa amrascae conidia discharged per hour from field-infected cadavers of cotton leafhoppers with and without light. 
after an average of $2.5 \mathrm{hr}$ exposure in the moisture chamber. An average of 26,372 conidia were counted from 5 cadavers without light source (mean time conidial production of $29 \mathrm{hr}$ ) compared to 5,290 conidia obtained with light source (mean time conidial production of 33 hr). A series of distinct conidial peak patterns were also observed in both set-up. The highest conidiation peak (without light source) was observed $7 \mathrm{hr}$ after exposure to high humidity chamber followed by 2 lower peaks 10 and $12 \mathrm{hr}$ thereafter. A rapid decline on intensity of conidial production was then recorded ending after $31 \mathrm{hr}$. On the other hand, highest peak for conidial production of cadavers (with light source) occurred $9 \mathrm{hr}$ after, followed by a slightly lower peak at 13 and $21 \mathrm{hr}$. Lower conidial counts were detected until conidiation terminated after $34 \mathrm{hr}$, ending relatively $3 \mathrm{hr}$ longer than,cadavers without light source. Thus, cadavers exposed to light source had very low conidial production and ended their conidiation for a longer time compared to cadavers unexposed to a light source. Apparently, the degree of epizootic occurrence, host and pathogen population, and the weather conditions in the area where and when the cadavers were collected had an effect on conidial production aside from the light requirements of the entomopathogen. The presence of primary, secondary and tertiary conidia were also observed projected by the cadavers. Primary conidia can be differentiated from secondary and tertiary conidia generally by their smaller size.

Several workers have attempted to characterize patterns of conidial discharge. The emergence of conidiophores of Entomophthorales usually occurs within a few hours of host death and discharge of conidia soon commences, (MacLeod, 1963). Cohn (1985) as cited by Mullens and Rodriguez (1985) noted that 
conidial discharge of Entomophthora muscae, for example, began sometime after $8 \mathrm{hr}$ postmortem (HPM) and that the cadaver remained swollen for a few days. Gustaffson (1965) further noted abundant conidiation at $30 \mathrm{hr}$ HPM in one muscoid fly. On the other hand, Carruthers (1982) observed that conidiation began in the field within a few hr of death, was most intense at $0100 \mathrm{hr}$, and was $95 \%$ complete by $0500 \mathrm{hr}$. Brobyn and Wilding (1983) reported that conidial germinătion occurred between 2 and $24 \mathrm{hr}$ after discharge.

It was further observed that if the fungus failed to contact a host, primary conidia of many species had the ability to form and forcibly discharge secondary conidia and tertiary (subsequent) conidia until fungal resources were exhausted. In the field, the hosts generally succumbed during the afternoon and early evening hours, and production of primary conidia was found to be most intense at night, particularly between 2400 and 0600 hours (Newman and Carner, 1974; Aoki, 1981; and Carruthers, 1982). This is generally the period of highest humidity, an important factor in many Entomophthorales (MacLeod 1963, Yendol, 1968, Wilding, 1969, and Millstein et al., 1983).

\section{Conidial Production of Laboratory-Infected Leafhopper Cadavers}

Compared to field-infected cadavers particularly those devoid of light source, conidial production in cadavers in the laboratory yielded very low counts (Fig. 2). Initial sporulation began $8 \mathrm{hr}$ for unexposed cadavers and $10 \mathrm{hr}$ for light-exposed ones after exposure to moisture, respectively. A slightly lower average conidial counts of 3,737 was observed from 5 cadavers without light source. The first highest peak occurred $15 \mathrm{hr}$ then followed at $2 \mathrm{hr}$ after. Cadavers exposed to 


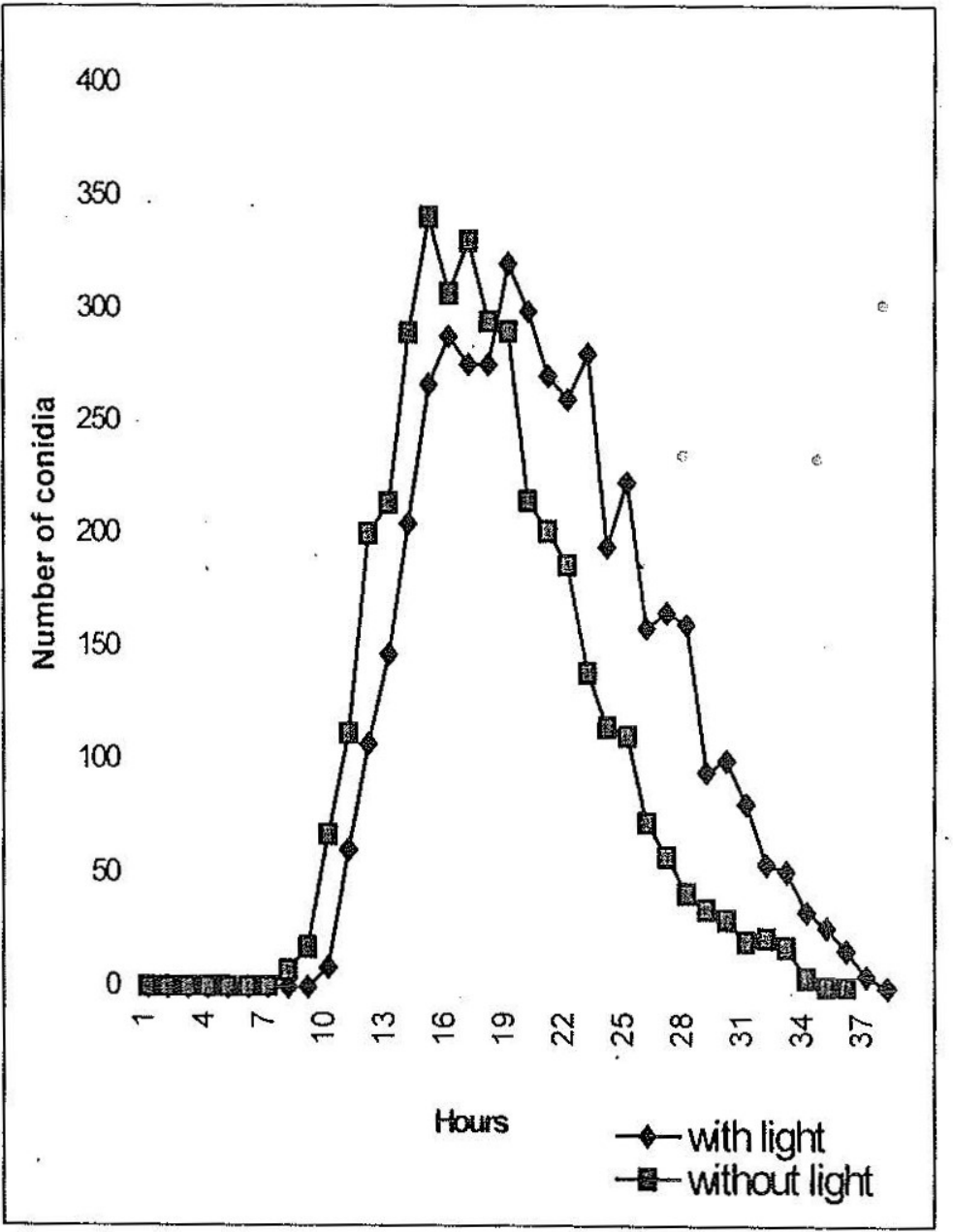

Figure 2. Average number of Batkoa amracae conidia discharge per hour from laboratory-infected cadavers of cotton leafhoppers with and without light source. 
light source yielded a slightly higher average conidial count of 4,447 until sporulation stopped. A series of conidial peaks was also observed in this set-up. The highest peak was observed $19 \mathrm{hr}$ after exposure to moisture. Sporulation ceased after $37 \mathrm{hr}$ while conidiation of cadavers under dark condition ended $2 \mathrm{hr}$ earlier. A small but significant shift in mean time of conidial production from cadavers aside from conidial counts in the two set-ups was notable. Such differences may indicate some alteration of the fungus due to difference in laboratory conditions as opposed to that in the field. Variability of light requirements in fungal sporulation had been reported in many species (Cochrane, 1958, as cited by Alexopoulus and Mims, 1979). It was further added that light plays an important role in spore dispersal since spore-bearing organs of many fungi are positively phototrophic and discharge their spores towards the light.

\section{CONCLUSION AND RECOMMENDATION}

Laboratory study on conidial discharge of cadavers showed higher average of 26,372 conidia from field-infected cadavers without light source (mean time conidial production of $29 \mathrm{hr}$ ) compared to only 5,290 conidia (meantime conidial production of $33 \mathrm{hr}$ ) for cadavers exposed to light source. On the other hand, conidial production of laboratory-infected cadavers was less intense. An average of 4,447 and 3,737 conidia were counted from cadavers exposed to light and without light source, respectively.

Results of this study provide basic information on the effect of light and duration of conidial production of field-infected or laboratoryinfected cadavers. This is important in the manipulation of field population if ever Batkoa amascae is used as a biological control agent. 
Subere

\section{LITERATURE CITED}

ALEXOPOULUS, C.J. and MIMS, C.W. 1979. Subdivision Zygonycolina. Chapter 9. pp 218-221. In: Introductory Mycology. $3^{\text {rd }}$ ed. John Wiley \& Sons, Inc.

AOKI, J. 1981. Patterns of conidial discharge of an Entomophthora species ("grylli" type) (Entomophthorales: Entomophthoraceae) from infected cadavers of Mamestra brassicae L. (Lepidoptera: Noctuidae). Appl. Entomol. Zool. 16: 216-224.

BROBYN, P.J. and WILDING, N. 1983. Invasive and developmental processes of Entomophthora muscae infecting houseflies (Musca domestica). Trans. Br. Mycol. Soc. 80:1-8.

CARRUTHERS, R.I. 1982. The biology and ecology of Entomophthora muscae (Cohn) in the onion agroecosystem. Ph.D. Dissertation. Michigan State University, East Lansing. 243 pp.

GUSTAFFSON, M. 1965. On species of the genus Entomophthora Fres. In Sweden. 1. Classification and Distribution. Lantbbrukshogs-kolans Ann. 31:103-212.

MaCLEOD, D.M. 1963. Entomophthorales infections. Pp. 189-231. In: Insect Pathology, An Advanced Treatise, E.A. Steinhaus (ed.) Vol. 2, Acad. Press, N.Y. 
MILLSTEIN, J.A., BROWN, G.C. and NORDIN, G.L. 1983. Microclimatic moisture and conidial production in Erynia sp. (Entomophthorales: Entomophthoraceae) In vivo moisture balance and conidiation phenology. Environ. Entomol. 12: $1339-1343$.

MULLENS, B.A. and RODRIQUEZ, J.L. 1985. Dynamics - of Entomophthora muscae

(Entomophthorales:

Entomophthoraceae) conidial discharge from Musca domestica (Biptera: Muscidae) cadavers. Environ. Entomol. 14(3): 317-322.

NEWMAN, G.G. and CARNER, G.R. 1974. Diel periodicity of Entomophthora gammae in soybean looper. Environ. Entomol. 3:888-890.

PETER, C. and DAVID, B.V. 1988. Evaluation of some insecticides for the control of major insect pests of okra and their side effects. Trop. Pest Mgt. 34(1): 76-80.

ULTHAMASAMY, S. 1986. Studies on the resistance in okra, Abelmoschus esculentus (L.) Moench to the leafhopper, Amrasca devastans(Dist.) Trop. Pest Mgt. 32(2): 146-147.

WILDING, N. 1969. Effect of humidity on the sporulation of Entomophthora aphids and E. thaxteriana. Trans. Br. Mycol. Soc. 53:126-130.

YENDOL, W.G. 1968. Factors affecting germination of Entomophthora conidia. J. Invertebr. Pathol. 10:116-121. 


\section{ABOUT THE AUTHOR}

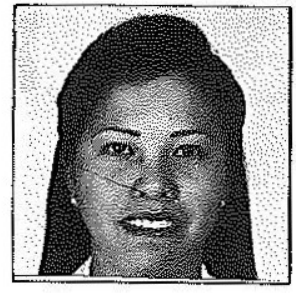

The author obtained her Bachelor of Science in Agriculture degree major in Plant Protection from the Visayas State College of Agriculture (ViSCA), ${ }^{\circ}$ Cum Laude, and her Master of Science degree major in Entomology in the Leyte State University (LSU).

Her previous work experiences include: University Research Associate at the Postharvest Horticulture Training and Research Center, UPLB, Laguna; Entomologist at the Nova Pacific Research Institute at the University of the Philippines (Visayas) in Miag-ao, Iloilo; and Instructor of the Negros State College of Agriculture (NSCA) in Kabankalan City, Negros Occidental.

She joined Dole Philippines, Inc. based in Polomolok, South Cotabato in February 1998 as Scientist at the Research and Plant Variety Department. Currently, she is on study leave to pursue her dóctoral program at the University of Hawaii in Manoa, Hawaii, USA. 